\title{
NMR Structure of the Natural Killer Cell Receptor 2B4 (CD244):
}

\author{
Implications for Ligand Recognition†,„‡ \\ James B. Ames ${ }^{*}$, Vinay Vyas, Jacqueline D. Lusin, and Roy Mariuzza \\ Center for Advanced Research in Biotechnology, University of Maryland Biotechnology Institute, \\ Rockville, Maryland 20850
}

\begin{abstract}
2B4, a transmembrane receptor expressed primarily on natural killer (NK) cells and on a subset of $\mathrm{CD} 8^{+} \mathrm{T}$ cells, plays an important role in activating NK-mediated cytotoxicity through its interaction with CD48 on target cells. We report here the atomic-resolution structure of the ligand-binding (D1) domain of 2B4 in solution determined by nuclear magnetic resonance (NMR) spectroscopy. The overall main chain structure resembles an immunoglobulin variable $(\mathrm{V})$ domain fold, very similar to that seen previously for domain 1 of CD2 and CD4. The structure contains nine $\beta$-strands assembled into two $\beta$-sheets conventionally labeled DEB and AGFCC'C". The six-stranded sheet (AGFCC'C") contains structural features that may have implications for ligand recognition and receptor function. A noncanonical disulfide bridge between Cys2 and Cys99 stabilizes a long and parallel $\beta$-structure between strand A (residues 3-12) and strand G (residues 100-108). A $\beta$-bulge at residues Glu45 and Ile 46 places a bend in the middle of strand $C^{\prime}$ that orients two conserved and adjacent hydrophobic residues (Ile46 and Leu47) inside the $\beta$-sandwich as seen in other V domains. Finally, the FG-loop (implicated in ligand recognition in the CD2-CD58 complex) is dynamically disordered in 2B4 in the absence of a ligand. We propose that ligand binding to $2 \mathrm{~B} 4$ might stabilize the structure of the FG-loop in the ligand complex.
\end{abstract}

Natural killer (NK) ${ }^{1}$ cells are a fundamental component of the innate immune system that play a vital role in the detection and destruction of virally infected and tumor cells $(1,2)$. The cytolytic activity of NK cells is regulated by a dynamic interplay between activating and inhibitory signals transmitted by distinct classes of receptors found on their surface. The dominant signal received by an NK cell through its interaction with normal levels of major histocompatibility complex (MHC) class I on target cells is inhibitory. When expression of MHC class I is reduced through infectious or tumorigenic processes, this inhibitory signal is attenuated, and the NK cell is activated. In this way, cells with abnormal MHC class I expression become targets of NK lytic activity that results from loss of inhibition of NK cell activation. Inhibitory receptors specific for MHC class I include the killer immunoglobulinlike receptors (KIRs), members of the Ly49 family, and the CD94/NKG2D family (3).

Activating receptors include 2B4, CD16, CD44, CD69, NKR-P1, NKp30, NKp44, and NKp46 $(1,2)$. However, only for some of these stimulatory receptors are the physiological ligands known: CD48 for 2B4 (4), IgG Fc for CD16 (5), and Clr for NKR-P1 (6). The balance between positive signaling receptors (resulting in target cell lysis) and negative signaling receptors (preventing lysis) ultimately determines the outcome of NK cell-target cell encounters $(1,2)$.

\footnotetext{
${ }^{\dagger}$ This work was supported by a Beckman Young Investigator Award (J.B.A.) and NIH Grants EY012347, NS045909 (J.B.A.), and AI47990 (R.M.).

₹Atomic coordinates have been deposited into the Protein Data Bank (accession no. 1Z2K.pdb).

*Corresponding author. Phone: (301) 738-6120. Fax: (301) 738-6255. E-mail: james@ carb.nist.gov.
} 
The activating NK receptor 2B4 is a transmembrane glycoprotein expressed primarily on NK cells, and on a subset of $\mathrm{CD}^{+} \mathrm{T}$ cells, that is involved in activating NK-mediated cytotoxicity (7-10). 2B4 comprises two Ig-like extracellular domains (D1 and D2) and a cytoplasmic portion containing a $\mathrm{CxC} /+$ motif that may bind a complementary $\mathrm{CxxC} /$-motif in the linker for activation of T cells (LAT) (11). By sequence homology, 2B4 is most closely related to the $\mathrm{CD} 2$ subgroup of the immununoglobulin (Ig) superfamily (Figure 1). The natural ligand for 2B4 is CD48 (4). As measured by surface plasmon resonance (SPR), soluble mouse CD48 binds to immobilized recombinant mouse $2 \mathrm{~B} 4$ with a $K_{\mathrm{D}}$ of $16 \mu \mathrm{M}$. The human counterpart of 2B4 was found to bind human CD48 with similar affinity $\left(K_{\mathrm{D}}=8 \mu \mathrm{M}\right)(4)$. These affinities are approximately 5 -fold higher than that of CD48 for CD2 $(12,13)$.

In addition to LAT, the cytoplasmic tail of 2B4 binds the $\mathrm{SH} 2$ domain-containing protein SAP (14). This association is crucial for $2 \mathrm{~B} 4$ to deliver activating signals to NK cells. Indeed, in the absence of SAP, 2B4 tranduces inhibitory signals that result in NK cell inactivation (7). This inhibition is mediated by the SHP-1 phosphatase, which competes with SAP for binding to 2B4. The 2B4 NK receptor has recently been associated with a severe, genetically inherited immune deficiency, termed X-linked lymphoproliferative disease (XLP), that is often characterized by Epstein-Barr virus (EBV)-induced lymphomas (7). In these patients, 2B4, upon binding CD48 on target cells, fails to activate, but instead inhibits, NK-mediated lysis of EBV-infected cells. The mutated gene responsible for XLP codes for SAP (15-17). In XLP NK cells, SAP is either truncated or missing and cannot associate with 2B4 (7). As a consequence, SHP-1 stably binds 2B4, contributing to the generation of a negative signal.

The finding that 2B4 can both activate and inhibit NK cytolysis, combined with the identification of CD48 as its biological ligand, makes 2B4 a compelling target for structural analysis. We present here the three-dimensional structure of the ligand-binding D1 domain of 2B4 by NMR methods. 2B4 adopts an immunoglobulin variable (V) domain fold, like that of domain 1 of CD2 and CD4 (Figure 1), but with several unique structural and dynamical features that could be related to ligand recognition and receptor function.

\footnotetext{
1 Abbreviations:

EDTA

ethylenediaminetetraacetic acid

HSQC

heteronuclear single quantum coherence

Ig

immunoglobulin

MHC

major histocompatibility complex

NK

natural killer

NOE

nuclear Overhauser effect

NOESY

nuclear Overhauser effect spectroscopy

rmsd

root-mean-squared deviation

TOCSY

total correlation spectroscopy
} 


\section{EXPERIMENTAL PROCEDURES}

\section{Protein Expression and Purification}

A DNA fragment encoding the ligand-binding domain of rat 2B4 (residues 1-112, referred to throughout the text as simply 2B4) was generated by PCR from the full-length rat gene and cloned into the bacterial expression vector pT7-7 (Novagen). The protein was expressed as inclusion bodies in Escherichia coli BL21(DE3) cells (Stratagene). Isotopically enriched protein was produced by growing cells in M9 minimal medium containing ${ }^{15} \mathrm{~N}$-labeled ammonium chloride and ${ }^{13} \mathrm{C}$-labeled glucose as sole nitrogen and carbon sources, respectively $(18,19)$. The cells were cultured at $37^{\circ} \mathrm{C}$ to an absorbance of $0.6-0.8$ at $600 \mathrm{~nm}$, and isopropyl$\beta$-D-thiogalactoside was added to a concentration of $1 \mathrm{mM}$. After incubation for $4 \mathrm{~h}$, the cells were resuspended in $100 \mathrm{mM}$ Tris- $\mathrm{HCl}(\mathrm{pH}$ 8.0) containing $2 \mathrm{mM}$ ETDA and $10 \mathrm{mM}$ DTT and lysed by two passes in a French Press at 1000 psi. Inclusion bodies were washed several times with $50 \mathrm{mM}$ Tris- $\mathrm{HCl}(\mathrm{pH} 8.0), 0.5 \%$ (v/v) Triton-X 100, $100 \mathrm{mM} \mathrm{NaCl}$, and $1 \mathrm{mM}$ ETDA, then solubilized in $100 \mathrm{mM}$ Tris- $\mathrm{HCl}$ (pH 8.0), $8 \mathrm{M}$ urea, $10 \mathrm{mM}$ EDTA, and $1 \mathrm{mM}$ DTT.

For in vitro folding, solubilized 2B4 D1 was diluted to a final concentration of $60-100 \mu \mathrm{g} / \mathrm{mL}$ into $0.8 \mathrm{M}$ arginine, $100 \mathrm{mM}$ Tris- $\mathrm{HCl}(\mathrm{pH} 8.0), 0.3 \mathrm{mM}$ reduced glutathione, $3 \mathrm{mM}$ oxidized glutathione, and $2 \mathrm{mM}$ EDTA. After 3-4 days at $4{ }^{\circ} \mathrm{C}$, the folding mixture was concentrated, dialyzed against $25 \mathrm{mM}$ Tris- $\mathrm{HCl}(\mathrm{pH} 8.0)$ and $100 \mathrm{mM} \mathrm{NaCl}$, and applied to a Superdex 75 HR size exclusion column (Amersham Biosciences). Further purification was carried out by anion exchange chromatography using a Mono Q column; the protein was eluted with a linear $\mathrm{NaCl}$ gradient. The buffer was exchanged to $100 \mathrm{mM}$ sodium phosphate ( $\mathrm{pH}$ 7.2) prior to NMR analysis.

\section{NMR Spectroscopy}

Samples for NMR analysis consisted of ${ }^{15} \mathrm{~N}$-labeled or ${ }^{13} \mathrm{C} /{ }^{15} \mathrm{~N}$-labeled $2 \mathrm{~B} 4(0.4 \mathrm{mM})$ in 0.3 $\mathrm{mL}$ of a $95 \% \mathrm{H}_{2} \mathrm{O} / 5 \%\left[{ }^{2} \mathrm{H}\right] \mathrm{H}_{2} \mathrm{O}$ solution containing $100 \mathrm{mM}$ sodium phosphate (pH 7.2). All NMR experiments were performed at $25^{\circ} \mathrm{C}$ on Bruker Avance 500 or $600 \mathrm{MHz}$ spectrometers equipped with a four-channel interface and triple-resonance probe with triple-axis pulsed field gradients. The ${ }^{15} \mathrm{~N}-{ }^{1} \mathrm{H}$ HSQC spectra (see Figure 2) were recorded on a sample of ${ }^{15} \mathrm{~N}$-labeled 2B4 (in 95\% $\mathrm{H} \mathrm{O}, 5 \%\left[{ }^{2} \mathrm{H}\right] \mathrm{H}_{2} \mathrm{O}$ ). The number of complex points and acquisition times were 256 and $180 \mathrm{~ms}\left({ }^{15} \mathrm{~N}\left(\mathrm{~F}_{1}\right)\right)$ and 512 and $64 \mathrm{~ms}\left({ }^{1} \mathrm{H}\left(\mathrm{F}_{2}\right)\right)$. All triple-resonance experiments were performed, processed, and analyzed as described $(19,20)$ on a sample of ${ }^{13} \mathrm{C} /{ }^{15} \mathrm{~N}$-labeled $2 \mathrm{~B} 4$ (in $95 \% \mathrm{H} \mathrm{O}, 5 \%\left[{ }^{2} \mathrm{H}\right] \mathrm{H}_{2} \mathrm{O}$ ) with the following number of complex points and acquisition times: $\mathrm{HNCO}\left\{{ }^{15} \mathrm{~N}\left(\mathrm{~F}_{1}\right) 32\right.$ and $23.7 \mathrm{~ms},{ }^{13} \mathrm{CO}\left(\mathrm{F}_{2}\right) 64$ and $42.7 \mathrm{~ms},{ }^{1} \mathrm{H}\left(\mathrm{F}_{3}\right) 512$ and $\left.64 \mathrm{~ms}\right\}$; HNCACB $\left\{{ }^{15} \mathrm{~N}\left(\mathrm{~F}_{1}\right) 32\right.$ and $23.7 \mathrm{~ms},{ }^{13} \mathrm{C}\left(\mathrm{F}_{2}\right) 48$ and $6.3 \mathrm{~ms},{ }^{1} \mathrm{H}\left(\mathrm{F}_{3}\right) 512$ and $\left.64 \mathrm{~ms}\right\}$; CBCACONNH $\left\{{ }^{15} \mathrm{~N}\left(\mathrm{~F}_{1}\right) 32\right.$ and $23.7 \mathrm{~ms},{ }^{13} \mathrm{C}\left(\mathrm{F}_{2}\right) 48$ and $6.3 \mathrm{~ms},{ }^{1} \mathrm{H}\left(\mathrm{F}_{3}\right) 512$ and $\left.64 \mathrm{~ms}\right\}$; HBHACONNH $\left\{{ }^{15} \mathrm{~N}\left(\mathrm{~F}_{1}\right) 32\right.$ and $23.7 \mathrm{~ms},{ }^{1} \mathrm{H}_{\mathrm{ab}}\left(\mathrm{F}_{2}\right) 64$ and $21 \mathrm{~ms},{ }^{1} \mathrm{H}\left(\mathrm{F}_{3}\right) 512$ and 64 $\mathrm{ms}\} .{ }^{15} \mathrm{~N}$-edited and ${ }^{13} \mathrm{C}$-edited NOESY-HSQC and TOCSY-HSQC experiments were performed as described previously $(21,22)$.

Triple resonance and NOESY spectra measured above were analyzed to determine resonance assignments and secondary structure of 2B4. The chemical shift index (see ref 23 for detailed description of the chemical shift index), ${ }^{3} \mathrm{~J}_{\mathrm{NH} \alpha}$ coupling constants, and Nuclear Overhauser Effect (NOE) connectivity patterns for each residue were analyzed and provided a measure of the overall secondary structure. Small ${ }^{3} J_{\mathrm{NH} \alpha}$ coupling constants $(<5 \mathrm{~Hz})$, strong NOE connectivities $(\mathrm{NN}(i, i+1)$ and $\alpha \mathrm{N}(i, i+3))$, and positive chemical shift index are characteristic of residues in an $\alpha$-helix. Conversely, large ${ }^{3} J_{\mathrm{NH} \alpha}$ coupling constants (>8 Hz), strong $\alpha \mathrm{N}(i, i$ $+1)$ and weak $\mathrm{NN}(i, i+1) \mathrm{NOE}$ connectivities, and negative chemical shift index are 
characteristic of residues in a $\beta$-strand. The results of the secondary structure analysis and topology of 2B4 are summarized schematically in Figure 1.

\section{Structure Calculation}

Backbone and side chain NMR resonances of 2B4 were assigned as described previously (20). Analysis of NOESY data determined nearly 1900 interproton distance relationships throughout the protein (19). The NMR-derived distances and dihedral angles then served as constraints (see Table 1) for calculating the three-dimensional structure of the protein using distance geometry and restrained molecular dynamics. Structure calculations were performed using the YASAP protocol within X-PLOR $(24,25)$, as described previously (26). A total of 1891 interproton distance constraints were obtained as described (20) by analysis of ${ }^{13} \mathrm{C}$-edited and ${ }^{15} \mathrm{~N}$-edited NOESY-HSQC spectra (100 ms mixing time) of ${ }^{13} \mathrm{C} /{ }^{15} \mathrm{~N}$-labeled $2 \mathrm{~B} 4$. In addition to the NOE-derived distance constraints, the following additional constraints were included in the structure calculation: 128 dihedral angle constraints ( $\phi$ and $\psi)$ and 170 distance constraints for 85 hydrogen bonds verified by identifying slowly exchanging amide protons in hydrogen-deuterium exchange experiments (18). Fifty independent structures were calculated, and the 15 structures of lowest energy were selected. The average total and experimental distance energies are 2969 and $249 \mathrm{kcal} \mathrm{mol}^{-1}$. The average root-mean-square (rms) deviations from an idealized geometry for bonds and angles are $0.0074 \AA$ and $2.25^{\circ}$. None of the distance and angle constraints were violated by more than $0.40 \AA$ or $4^{\circ}$, respectively.

\section{RESULTS AND DISCUSSION}

The ${ }^{1} \mathrm{H}_{-}{ }^{15} \mathrm{~N}$ HSQC NMR spectrum of ${ }^{15} \mathrm{~N}$-labeled 2B 4 exhibited close to the expected number of backbone amide resonances (101 out of 105), suggesting that the protein is stably folded (Figure 2). Pulsed field gradient NMR diffusion studies (27) confirmed a protein monomer in solution under NMR conditions. More than $90 \%$ of the NMR resonances had very sharp and uniform peak intensities and were assigned as indicated in Figure 2. The assigned peaks in the spectrum represent main-chain and side-chain amide groups that serve as fingerprints of overall conformation. Three-dimensional structures of 2B4 were calculated on the basis of NOE data, slowly exchanging amide NH groups, chemical shift analysis, and ${ }^{3} J_{\mathrm{NH} \alpha}$ spin-spin coupling constants (see Experimental Procedures). The analysis of chemical shift index (CSI) (28), ${ }^{3} J_{\mathrm{NH} \alpha}(29)$, and short-range NOEs (30) is illustrated in Figure 1A and revealed at least nine $\beta$-strands and one short $\alpha$-helix. The final three-dimensional structures of 2B4 derived from the NMR data are superimposed and illustrated in Figure 3A (atomic coordinates have been deposited in the RSCB Protein Databank). Table 1 summarizes the structural statistics calculated for the 15 lowest energy conformers.

The NMR-derived 2B4 structures (Figure 3B,C) clearly showed a fold like that of an immunoglobulin $\mathrm{V}$ domain seen previously in the structures of domain 1 of $\mathrm{CD} 2(31,32)$ and CD4 $(33,34)$. The 2B4 structure contains nine $\beta$-strands (see Figure 1A for residue definition of individual strands). The overall topology consists of two $\beta$-sheets of strands labeled DEB and AGFCC'C" (Figure 1B). The two $\beta$-sheets in 2B4 are similar to those of CD2 and CD4 and differ somewhat from the more conventional four-stranded (ABED) and six-stranded (A'GFCC'C') $\beta$-sheets observed in the majority of other V domains (35).

The three-stranded $\beta$-sheet (DEB) is somewhat shorter in length than that of CD2 and CD4. Strand B in 2B4 is flanked on both ends by proline (Pro16 and Pro21), which lacks a mainchain amide proton and destabilizes the hydrogen-bonding interaction with strand $\mathrm{E}$. The length of the three-stranded sheet is also shortened by the disordered connecting loop between strands $\mathrm{D}$ and $\mathrm{E}$ (residues 68-72). 
The six-stranded $\beta$-sheet (AGFCC'C") of 2B4 forms a curved (saddle-like) outer surface implicated in ligand binding in other $\mathrm{V}$ domains $(32,36)$. In $2 \mathrm{~B} 4$, strands $\mathrm{A}$ and $\mathrm{G}$ are connected in a parallel fashion by main-chain hydrogen bonds and a disulfide bridge between Cys 2 and Cys99. Strands F and $\mathrm{G}$ form a hairpin $\beta$-structure with a connecting FG-loop (residues 92-97) that appears dynamically disordered (very broad NMR peaks) and whose structure is not accurately defined by the current NMR data. Preliminary NMR relaxation analysis of the FGloop suggested significant internal dynamics on the subnanosecond time scale (data not shown), consistent with a highly disordered main chain. Interestingly, this long and unstructured FG-loop contains residues that are believed to play a role in ligand binding based on the closely related crystal structure of the CD2-CD58 complex (36). Strands C and C' form a hairpin $\beta$-structure connected by a well-defined CC'-loop (residues 37-42) that might also play a role in ligand binding $(32,36)$. Strand $C^{\prime}$ is interrupted by a $\beta$-bulge at Glu45 and Ile 46 , forming two shorter strands, $\mathrm{C}_{1}$ ' and $\mathrm{C}_{2}$ ' (Figure 1). The $\beta$-bulge disrupts the register of mainchain hydrogen bonds between strands $\mathrm{C}$ and C' (Figure 4). Strand $\mathrm{C}_{1}$ ' connects to strand $\mathrm{C}$ by main-chain hydrogen bonds between Lys 35 and Ile 44 . The $\beta$-bulge prevents hydrogen bonding between Trp33 and Ile 46 and shifts the register of the two strands by one residue. As a consequence, strand $\mathrm{C}_{2}$ ' connects to strand $\mathrm{C}$ by main-chain hydrogen bonds between $\operatorname{Trp} 33$ and Leu47 and between Val31 and Trp49. The $\beta$-bulge allows two adjacent hydrophobic side chains (Ile46 and Leu47) to point in the same direction, inside the $\beta$-sandwich (Figures 3C and 4) that otherwise would point in opposite directions in an extended main-chain conformation. A similar $\beta$-bulge in strand C' has been described for CD2 and CD4 and is believed to make the GFCC' sheet curved (35). Strands $\mathrm{C}_{2}$ ' and C" form a hairpin $\beta$-structure connected by a sharp, two-residue $\beta$-turn that is somewhat different from the longer C'C'-loop seen in some $\mathrm{V}$ domains. Finally, Asp1 at the $\mathrm{N}$-terminus and the last three residues at the $\mathrm{C}$-terminus (residues 110-112) are unstructured and not defined by the NMR data.

The two $\beta$-sheets (DEB and AGFCC'C') of 2B4 are connected by a short helix (residues 81-84) and three connecting loops (AB-, BC-, and C'D-loops). The structure of these intersheet regions is poorly defined by the NMR data, perhaps due to dynamics. Indeed, the NMR line widths and relaxation properties for residues in the connecting loops (AB-, BC-, and C'Dloops) suggest conformational fluctuations on the chemical shift time scale. The dynamical properties of the intersheet loops indicate conformational elasticity between the two $\beta$-sheets that might play a role in ligand recognition.

The overall main-chain structure of the $\beta$-sheet regions of $2 \mathrm{~B} 4$ (DEB and AGFCC' $C^{\prime \prime}$ ) is similar to that in domain 1 of $\mathrm{CD} 2$ and CD4. The rmsd alignment of main-chain atoms in the $\beta$-sheet regions is $2.4 \AA$, comparing $2 \mathrm{~B} 4$ and $\mathrm{CD} 2$, and $2.7 \AA$, comparing $2 \mathrm{~B} 4$ and CD4. The two $\beta$ sheets of $2 \mathrm{~B} 4, \mathrm{CD} 2$, and $\mathrm{CD} 4$ are somewhat different from the canonical four-stranded (ABED) and six-stranded (A'GFCC'C') $\beta$-sheets found in conventional V domains (35). Normally, the $\mathrm{N}$-terminal region of strand $\mathrm{A}$ forms antiparallel $\beta$-structure with strand $\mathrm{B}$ in the four-stranded sheet, whereas the C-terminal end of strand A (A') forms a parallel interaction with strand $\mathrm{G}$ in the six-stranded sheet. The structures of $2 \mathrm{~B} 4, \mathrm{CD} 2$, and $\mathrm{CD} 4$ completely lack the antiparallel interaction between strands $\mathrm{A}$ and $\mathrm{B}$. Instead, strand $\mathrm{A}$ in $2 \mathrm{~B} 4$ is quite long (nine residues in $2 \mathrm{~B} 4$ vs five residues in CD4) and is held in an unusually long parallel $\beta$-structure with strand G due to a noncanonical disulfide bridge between Cys 2 and Cys 99 . The long parallel $\beta$-structure between strands A and G may help stabilize the convex outer curvature of the six-stranded $\beta$ sheet (AGFCC'C').

2B4 has unique structural features that may be important for ligand recognition. The structure of the $\mathrm{CC}^{\prime}$ and $\mathrm{FG}$ loop regions differ substantially in 2B4 and domain 1 of $\mathrm{CD} 2$ (Figure 5A). These loops are not conserved in sequence or length. The CC' and FG-loops have been implicated previously in ligand binding $(32,36)$. The marked structural differences between 2B4 and CD2 in Figure 5A suggests that the CC' - and FG-loops might, in part, explain ligand 
specificity. The FG-loop in 2B4 is dynamically disordered in our structure, perhaps because ligand binding is needed to stabilize its structure. The dynamics of the FG-loop might suggest an induced-fit mechanism for ligand recognition by $2 \mathrm{~B} 4$. In addition, $2 \mathrm{~B} 4$ has a noncanonical disulfide bridge at Cys 2 and Cys99 that stabilizes a long and parallel $\beta$-sheet between strands $\mathrm{A}$ and $\mathrm{G}$, causing a convex or saddle-like curvature to the outer surface of the six-stranded $\beta$ sheet (AGFCC'C'). Finally, the C'-strand in 2B4 is interrupted by a $\beta$-bulge that causes two adjacent hydrophobic side chains (Ile46 and Leu47) to point in the same direction, inside the $\beta$-sandwich (Figure 3C,D).

\section{Implications for Ligand Recognition}

The structural interaction of 2B4 with its biological ligand, CD48 (D1-domain), was modeled on the basis of our current structure of 2B4 and the crystal structure of the CD2-CD58 complex (Figure 5B). The D1 domain of CD48 is $\sim 28 \%$ identical ( $45 \%$ homologous) in primary sequence to that of CD58 (Figure 1A) whose three-dimensional structure is known $(36,37)$. An approximate three-dimensional structure of the D1 domain of CD48 was calculated by homology modeling based on the known structure of CD58 using the InsightII/Discover/ Homology program (BIOSYM Technology, San Diego, CA). The modeled structure of CD48 was then docked onto our current structure of $2 \mathrm{~B} 4$ by first overlaying (in a least squares fashion) the CD48 structure on top of CD58 in the CD2-CD58 complex (36), followed by a similar alignment of the $2 \mathrm{~B} 4$ structure with respect to $\mathrm{CD} 2$ in the complex. This alignment procedure places 2B4 in close proximity to $\mathrm{CD} 48$ with the same relative orientation as defined in the CD2-CD58 complex. The six-stranded $\beta$-sheet (AGFCC'C") of 2B4 interacts face-to-face with the corresponding $\beta$-sheet of $\mathrm{CD} 48$. This interface lacks many of the intermolecular salt-bridge interactions between charged side chains that are evident in the CD2-CD58 complex. The charged, interfacial residues of CD2 (Asp31, Asp32, Lys34, Glu36, Lys43, Arg48, Lys51, and Lys82) and CD58 (Glu25, Lys29, Lys32, Asp33, Lys34, Glu37, Glu39, Glu42, Arg44, Glu76, Glu78, and Asp84) are not conserved in 2B4 and CD48, respectively. Therefore, the 2B4-CD48 interface does not possess many intermolecular electrostatic contacts, but instead is stabilized more by intermolecular hydrophobic and/or hydrogen-bonding interactions.

The modeled structure of the 2B4-CD48 complex suggests that the FG-loop of 2B4 is located very close to the CC'-loop of CD48 (Figure 5). The FG-loop of 2B4 (in the absence of ligand) is dynamically disordered in our NMR analysis, so the FG loop structure of 2B4 shown in Figure 5 represents the energy-minimized average structure in solution. We propose that the dynamical properties of the FG-loop would allow it to sample a wide range of conformations that rapidly select an optimum conformation for recognizing the CC'-loop of CD48. There is growing evidence that regions of structural flexibility may represent likely sites for receptor binding as demonstrated by the interaction of the NK receptor, NKG2D, with the MHC-like molecule, MICA. The receptor-binding site on MICA is disordered in the crystal structure of the free ligand but adopts an $\alpha$-helical conformation upon binding to NKG2D (38).

Another striking feature of the 2B4-CD48 complex (Figure 5) was the finding that the CC'loop of 2B4 is not located close to the FG-loop of CD48, unlike what is found in the CD2CD58 complex. The $\beta$-bulge in 2B4 (Figure 4) places a bend in the middle of the $\mathrm{C}^{\prime}$-strand that displaces the CC'-loop of 2B4 downward with respect to the CC' loop of CD2 (Figure $5 \mathrm{~A}$ ). This downward disposition places the CC'-loop of 2B4 quite far from the FG-loop of CD48 in the complex. One interpretation is that ligand binding might reorient 2B4 as a whole in the complex that would place its CC'-loop in closer contact with the FG-loop of CD48. Alternatively, ligand binding might induce a local conformational change in 2B4 near the $\beta$ bulge that would move the CC'-loop upward to adopt a structure more akin to that of CD2 in the complex. 
In summary, we determined the three-dimensional structure of the ligand-binding D1 domain of 2B4 in solution by NMR (Figure 3) and proposed a modeled structure of the 2B4-CD48

complex (Figure 5). Our analysis revealed unique structural and dynamical properties of 2B4 (in the CC'- and FG-loops), perhaps implying ligand-induced conformational changes in 2B4 that might promote ligandspecific contacts. The implications of these results for ligand recognition will be tested more rigorously in the future by site-directed mutagenesis analysis (of the CC' - and FG-loops), ligand-induced chemical shift changes, and by ultimately determining the atomic-resolution structure of the 2B4-CD48 complex.

\section{ACKNOWLEDGMENT}

We are grateful to Dr. Vinay Kumar (University of Chicago) for providing the $2 \mathrm{~B} 4 \mathrm{cDNA}$, Dr. Nese Sari for help with NMR experiments, and Frank Delaglio for writing computer software for NMR data processing and analysis.

\section{REFERENCES}

1. McQueen KL, Parham P. Variable receptors controlling activation and inhibition of NK cells. Curr. Opin. Immunol 2002;14:615-621. [PubMed: 12183162]

2. Yokoyama WM, Plougastel BF. Immune functions encoded by the natural killer gene complex. Nat. Rev. Immunol 2003;3:304-316. [PubMed: 12669021]

3. Natarajan K, Dimasi N, Wang J, Mariuzza RA, Margulies DH. Structure and function of natural killer cell receptors: multiple molecular solutions to self, nonself-discrimination. Annu. Rev. Immunol 2002;20:853-885. [PubMed: 11861620]

4. Brown MH, Boles K, van der Merwe PA, Kumar V, Mathew PA, Barclay AN. 2B4, the natural killer and $\mathrm{T}$ cell immunoglobulin superfamily surface protein, is a ligand for CD48. J. Exp. Med 1998;188:2083-2090. [PubMed: 9841922]

5. Perussia B, Starr S, Abraham S, Fanning V, Trinchieri G. Human natural killer cells analyzed by B73.1, a monoclonal antibody blocking $\mathrm{Fc}$ receptor functions. I. Characterization of the lymphocyte subset reactive with B73.1. J. Immunol 1983;130:2133-2141. [PubMed: 6833758]

6. Iizuka K, Naidenko OV, Plougastel BF, Fremont DH, Yokoyama WM. Genetically linked C-type lectin-related ligands for the NKRP1 family of natural killer cell receptors. Nat. Immunol 2003;4:801807. [PubMed: 12858173]

7. Parolini S, Bottino C, Falco M, Augugliaro R, Giliani S, Franceschini R, Ochs HD, Wolf H, Bonnefoy JY, Biassoni R, Moretta L, Notarangelo LD, Moretta A. X-linked lymphoproliferative disease. 2B4 molecules displaying inhibitory rather than activating function are responsible for the inability of natural killer cells to kill Epstein-Barr virus-infected cells. J. Exp. Med 2000;192:337-346. [PubMed: 10934222]

8. Biassoni R, Cantoni C, Pende D, Sivori S, Parolini S, Vitale M, Bottino C, Moretta A. Human natural killer cell receptors and co-receptors. Immunol. Rev 2001;181:203-214. [PubMed: 11513142]

9. Boles KS, Stepp SE, Bennett M, Kumar V, Mathew PA. 2B4 (CD244) and CS1: novel members of the CD2 subset of the immunoglobulin superfamily molecules expressed on natural killer cells and other leukocytes. Immunol. Rev 2001;181:234-249. [PubMed: 11513145]

10. McNerney ME, Lee KM, Kumar V. 2B4 (CD244) is a non-MHC binding receptor with multiple functions on natural killer cells and CD8(+) T cells. Mol. Immunol 2005;42:489-494. [PubMed: 15607804]

11. Bottino C, Augugliaro R, Castriconi R, Nanni M, Biassoni R, Moretta L, Moretta A. Analysis of the molecular mechanism involved in 2B4-mediated NK cell activation: evidence that human 2B4 is physically and functionally associated with the linker for activation of T cells. Eur. J. Immunol 2000;30:3718-3722. [PubMed: 11169415]

12. van der Merwe PA, Barclay AN, Mason DW, Davies EA, Morgan BP, Tone M, Krishnam AK, Ianelli C, Davis SJ. Human cell-adhesion molecule CD2 binds CD58 (LFA-3) with a very low affinity and an extremely fast dissociation rate but does not bind CD48 or CD59. Biochemistry 1994;33:10149_ 10160. [PubMed: 7520278] 
13. Davis SJ, Ikemizu S, Wild MK, van der Merwe PA. CD2 and the nature of protein interactions mediating cellcell recognition. Immunol. Rev 1998;163:217-236. [PubMed: 9700513]

14. Tangye SG, Lazetic S, Woollatt E, Sutherland GR, Lanier LL, Phillips JH. Cutting edge: human 2B4, an activating NK cell receptor, recruits the protein tyrosine phosphatase SHP-2 and the adaptor signaling protein SAP. J. Immunol 1999;162:6981-6985. [PubMed: 10358138]

15. Nichols KE, Harkin DP, Levitz S, Krainer M, Kolquist KA, Genovese C, Bernard A, Ferguson M, Zuo L, Snyder E, Buckler AJ, Wise C, Ashley J, Lovett M, Valentine MB, Look AT, Gerald W, Housman DE, Haber DA. Inactivating mutations in an SH2 domain-encoding gene in X-linked lymphoproliferative syndrome. Proc. Natl. Acad. Sci. U.S.A 1998;95:13765-13770. [PubMed: 9811875]

16. Coffey AJ, Brooksbank RA, Brandau O, Oohashi T, Howell GR, Bye JM, Cahn AP, Durham J, Heath P, Wray P, Pavitt R, Wilkinson J, Leversha M, Huckle E, Shaw-Smith CJ, Dunham A, Rhodes S, Schuster V, Porta G, Yin L, Serafini P, Sylla B, Zollo M, Franco B, Bentley DR. Host response to EBV infection in X-linked lymphoproliferative disease results from mutations in an SH2domain encoding gene. Nat. Genet 1998;20:129-135. [PubMed: 9771704]

17. Sayos J, Wu C, Morra M, Wang N, Zhang X, Allen D, van Schaik S, Notarangelo L, Geha R, Roncarolo MG, Oettgen H, De Vries JE, Aversa G, Terhorst C. The X-linked lymphoproliferative-disease gene product SAP regulates signals induced through the co-receptor SLAM. Nature 1998;395:462-469. [PubMed: 9774102]

18. Ames JB, Tanaka T, Stryer L, Ikura M. Secondary structure of myristoylated recoverin determined by three-dimensional heteronuclear NMR: implications for the calcium-myristoyl switch. Biochemistry 1994;33:10743-10753. [PubMed: 8075075]

19. Clore GM, Gronenborn AM. NMR structures of proteins and protein complexes beyond 20,000 M (r). Nat. Struct. Biol 1997;4:849-853. [PubMed: 9377157]

20. Tanaka T, Ames JB, Kainosho M, Stryer L, Ikura M. Differential isotype labeling strategy for determining the structure of myristoylated recoverin by NMR spectroscopy. J. Biomol. NMR 1998;11:135-152. [PubMed: 9679292]

21. Talluri S, Wagner G. An optimized 3D NOESY-HSQC. J. Magn. Reson., Ser. B 1996;112:200-205. [PubMed: 8812906]

22. Muhandiram DR, Farrow NA, Xu G, Smallcombe SH, Kay LE. A gradient NOESY-HSQC experiment for recording NOESY spectra of proteins dissolved in $\mathrm{H}_{2} \mathrm{O}$. J. Magn. Reson., Ser. B 1993;102:317-321.

23. Wishart DS, Sykes BD, Richards FM. The chemical shift index: a fast and simple method for the assignment of protein secondary structure through NMR spectroscopy. Biochemistry 1992;31:16471651. [PubMed: 1737021]

24. Brünger, AT. X-PLOR, Version 3.1: A System for X-ray Crystallography and NMR. Yale University Press; New Haven, CT: 1992.

25. Badger J, Kumar RA, Yip P, Szalma S. New features and enhancements in the X-PLOR computer program. Proteins 1999;35:25-33. [PubMed: 10090283]

26. Bagby S, Harvey TS, Eagle SG, Inouye S, Ikura M. NMR-derived three-dimensional solution structure of protein S complexed with calcium. Structure 1994;2:107-122. [PubMed: 8081742]

27. Altieri AS, Hinton DP, Byrd RA. Association of biomolecular systems via pulsed field gradient NMR selfdiffusion measurements. J. Am. Chem. Soc 1995;117:7566-7567.

28. Wishart DS, Sykes BD, Richards FM. Relationship between nuclear magnetic resonance chemical shift and protein secondary structure. J. Mol. Biol 1991;222:311-333. [PubMed: 1960729]

29. Anglister J, Grzesiek S, Wang AC, Ren H, Klee CB, Bax A. ${ }^{1} \mathrm{H},{ }^{13} \mathrm{C},{ }^{15} \mathrm{~N}$ nuclear magnetic resonance backbone assignments and secondary structure of human calcineurin B. Biochemistry 1994;33:35403547. [PubMed: 8142351]

30. Wuthrich, K. NMR of Proteins and Nucleic Acids. John Wiley and Sons, Inc.; New York: 1986.

31. Driscoll PC, Cyster JG, Campbell ID, Williams AF. Structure of domain 1 of rat T lymphocyte CD2 antigen. Nature 1991;353:762-765. [PubMed: 1682812]

32. Jones EY, Davis SJ, Williams AF, Harlos K, Stuart DI. Crystal structure at $2.8 \AA$ resolution of a soluble form of the cell adhesion molecule CD2. Nature 1992;360:232-239. [PubMed: 1279440] 
33. Wang JH, Yan YW, Garrett TP, Liu JH, Rodgers DW, Garlick RL, Tarr GE, Husain Y, Reinherz EL, Harrison SC. Atomic structure of a fragment of human CD4 containing two immunoglobulin-like domains. Nature 1990;348:411-418. [PubMed: 1701030]

34. Wu H, Myszka DG, Tendian SW, Brouillette CG, Sweet RW, Chaiken IM, Hendrickson WA. Kinetic and structural analysis of mutant CD4 receptors that are defective in HIV gp120 binding. Proc. Natl. Acad. Sci. U.S.A 1996;93:15030-15035. [PubMed: 8986758]

35. Harpaz Y, Chothia C. Many of the immunoglobulin superfamily domains in cell adhesion molecules and surface receptors belong to a new structural set which is close to that containing variable domains. J. Mol. Biol 1994;238:528-539. [PubMed: 8176743]

36. Wang JH, Smolyar A, Tan K, Liu JH, Kim M, Sun ZY, Wagner G, Reinherz EL. Structure of a heterophilic adhesion complex between the human CD2 and CD58 (LFA-3) counterreceptors. Cell 1999;97:791-803. [PubMed: 10380930]

37. Ikemizu S, Sparks LM, van der Merwe PA, Harlos K, Stuart DI, Jones EY, Davis SJ. Crystal structure of the CD2-binding domain of CD58 (lymphocyte functionassociated antigen 3) at 1.8-Å resolution. Proc. Natl. Acad. Sci. U.S.A 1999;96:4289-4294. [PubMed: 10200255]

38. Li P, Morris DL, Willcox BE, Steinle A, Spies T, Strong RK. Complex structure of the activating immunoreceptor NKG2D and its MHC class I-like ligand MICA. Nat. Immunol 2001;2:443-451. [PubMed: 11323699] 
A

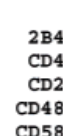

$2 \mathrm{~B} 4$
$\mathrm{CD} 4$
$\mathrm{CD} 2$

CD58

${ }^{3} \mathrm{~J}_{\mathrm{RHa}}$

dow $(i, i+1)$

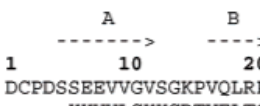

KKVVLGKKGDTVELTCTASOKKS, . VSVQWKKTEQGSHRKIEIL.

KBITNALETWGALGQDINLDIPSFQMSDDIDDI KWEKT. .SDKKKIA . .

QGHLVHMTVVSGSNVTLNI . SESLPENYKQLTWFYT . . FDQKIVE. .

FSQQIYGVVYGNVTFHV, PSNVP, . LKEVLWKKO , KD. KVAB . .
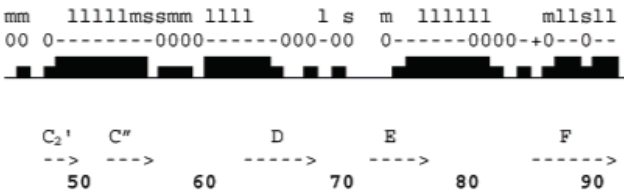

50

90

.... NWYNDGPSWSNYSFSDIYG. FDYGDFALSIKSAKLQDSGHYLLITTN NQGSFLTKGPSKLNDRADSRRSLWDOGNFPLI I KNL KI EDSDTYICEVED QFRKEKETF . KEKDTYKLF KNG TLKIKHLKTDDPDIYKVSIYD QR ....WDSRKSKY.

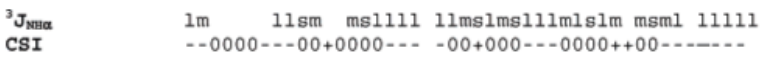

doos $(i, i+1)$
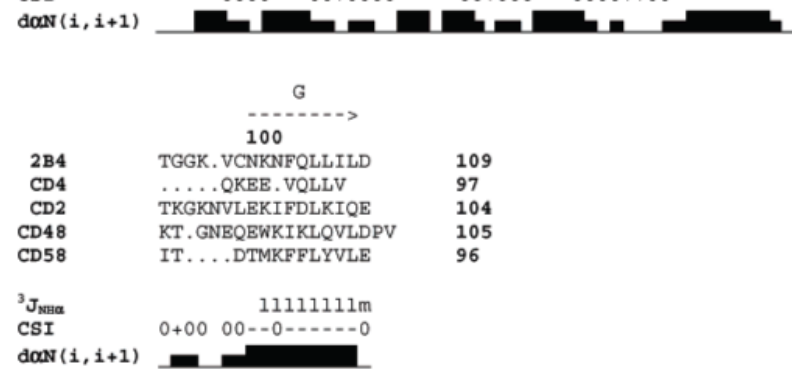

B

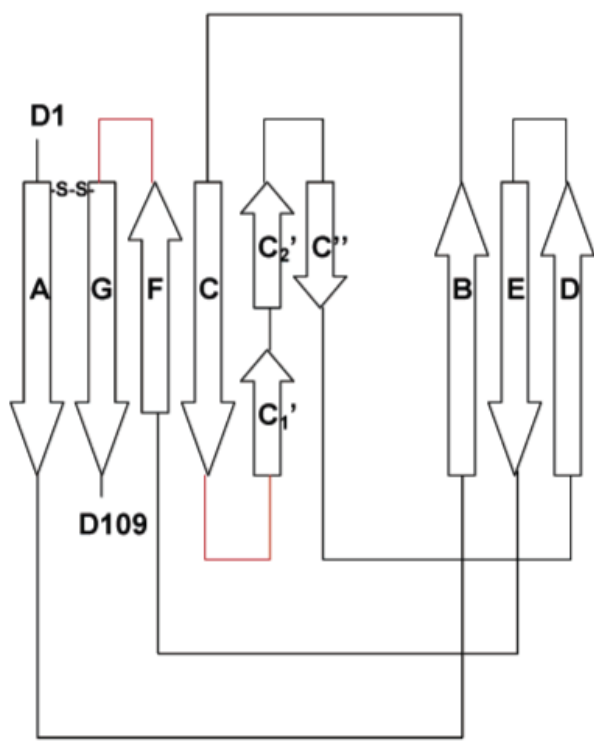

Figure 1.

(A) Amino acid sequence alignment of immunoglobulin $\mathrm{V}$ domains for rat 2B4 (accession no. Q9JLM2), human CD2, human CD4, human CD48, and human CD58. Residue definition of $\beta$-strand regions are indicated by arrows. Conserved residues are highlighted in bold. The chemical shift index (CSI) of each residue $(-1,0,+1)$ is represented by,- 0 , or + , respectively. The ${ }^{3} J_{\mathrm{NH} \alpha}$ coupling constants are denoted as "large" $(1,>8 \mathrm{~Hz})$, "medium" $(\mathrm{m}, 5-8 \mathrm{~Hz})$, and "small" (s, <5 Hz). Sequential NOE connectivities $(\mathrm{d} \alpha \mathrm{N}(i, i+1))$ are represented as strong, weak, or zero intensity in bar graphs. (B) Schematic representation of $\beta$-sheet topology. 


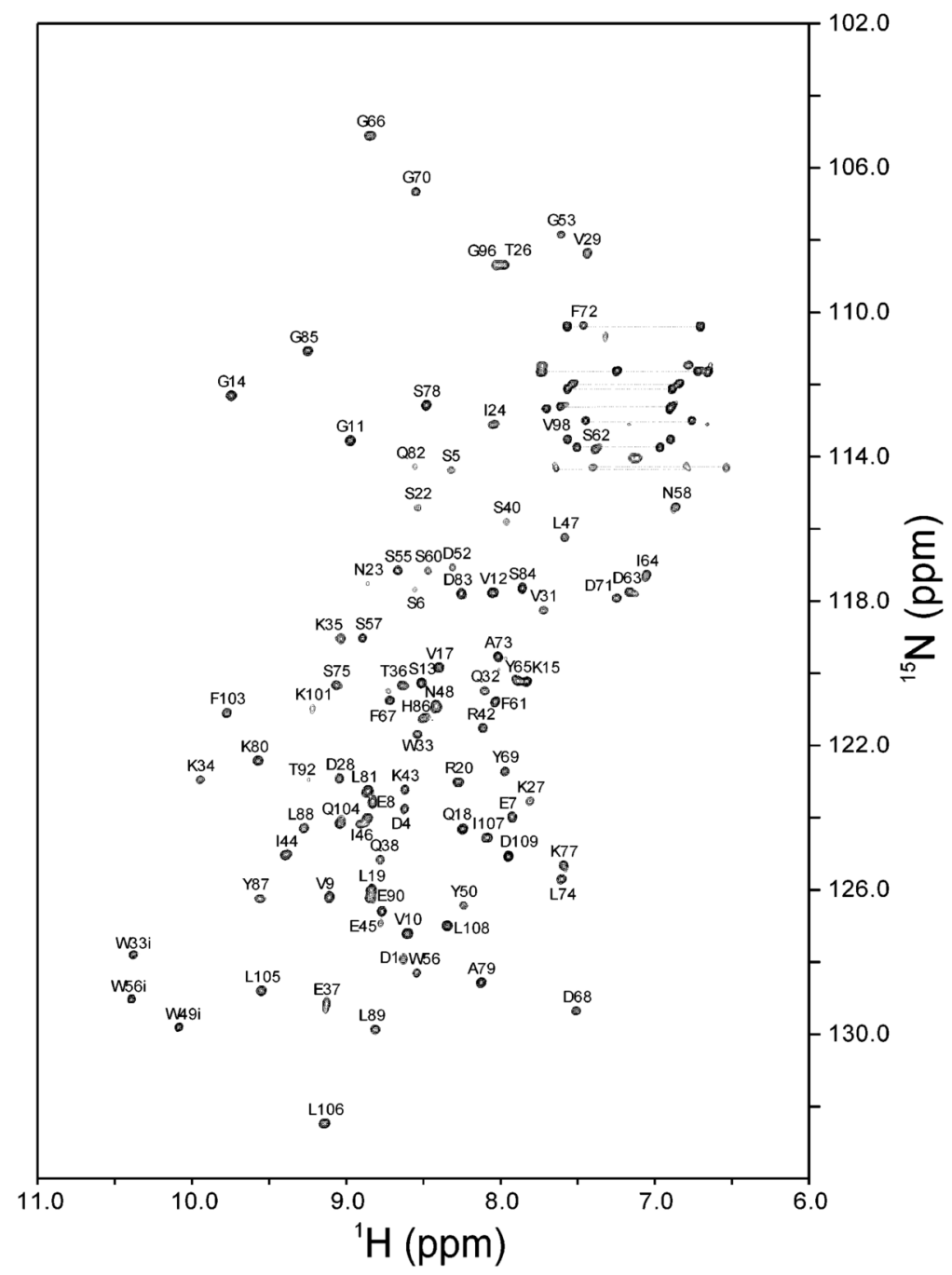

Figure 2.

${ }^{1} \mathrm{H}-{ }^{15} \mathrm{~N}$ HSQC NMR spectrum of $2 \mathrm{~B} 4$. Peaks corresponding to the $\mathrm{NH}_{2}$-groups of the sidechain amides of Gln and Asn residues are connected by dotted lines. Sequence-specific assignments are indicated and deposited to the BioMagResBank Repository (BMRB accession no. 6538). 

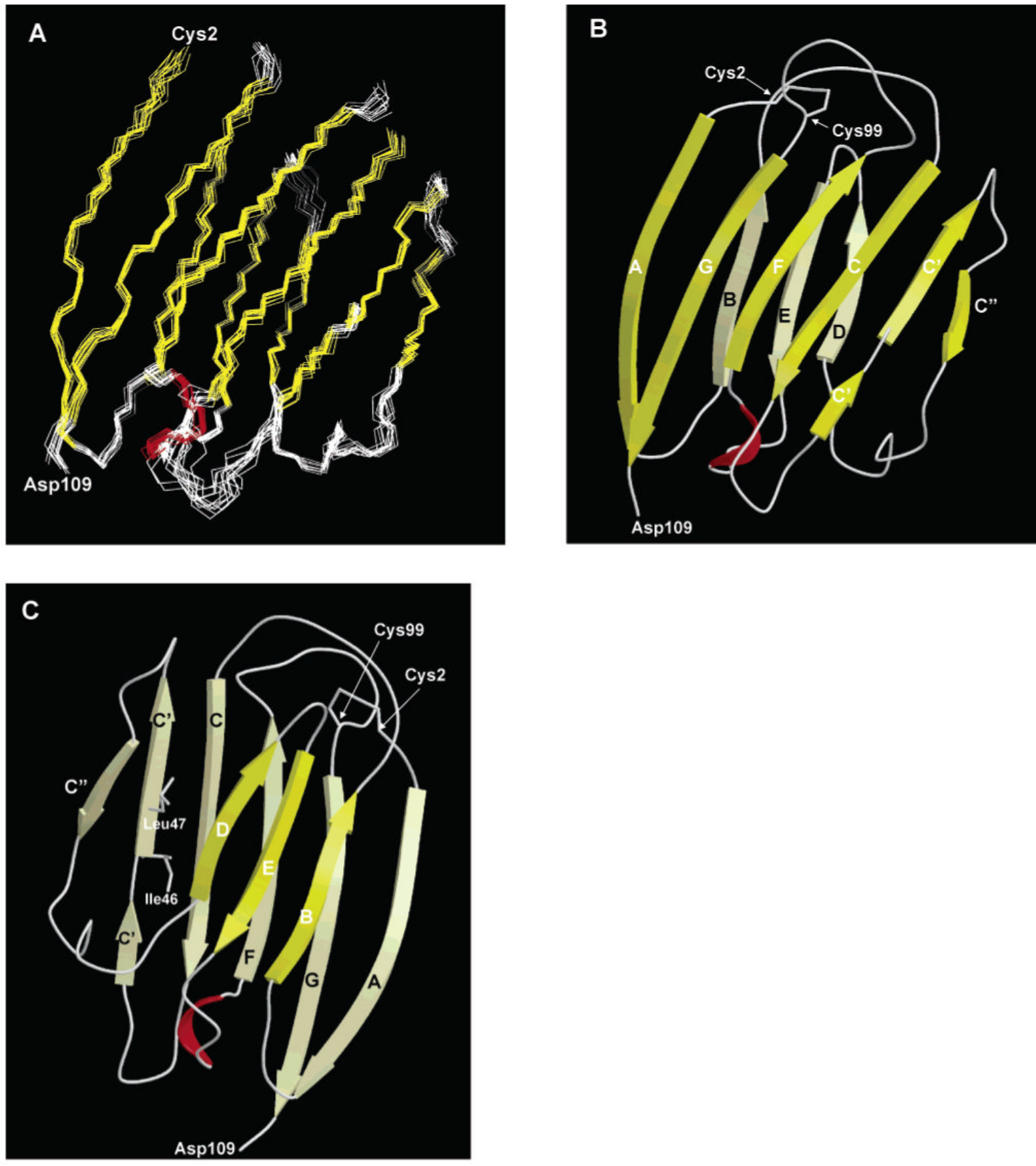

Figure 3.

Main-chain structure of 2B4 in solution determined by NMR ${ }^{2}$. (A) Superposition of mainchain atoms of the 15 lowest energy calculated structures. (B) Ribbon representation of the energy-minimized average main-chain structure and side-chain atoms of cysteine residues. (C) A $180^{\circ}$ rotation of $\mathrm{B}$. The FG-loop (residues $92-97$ ) is dynamically unstructured and not shown in A. $\beta$-strand regions are highlighted in yellow. 


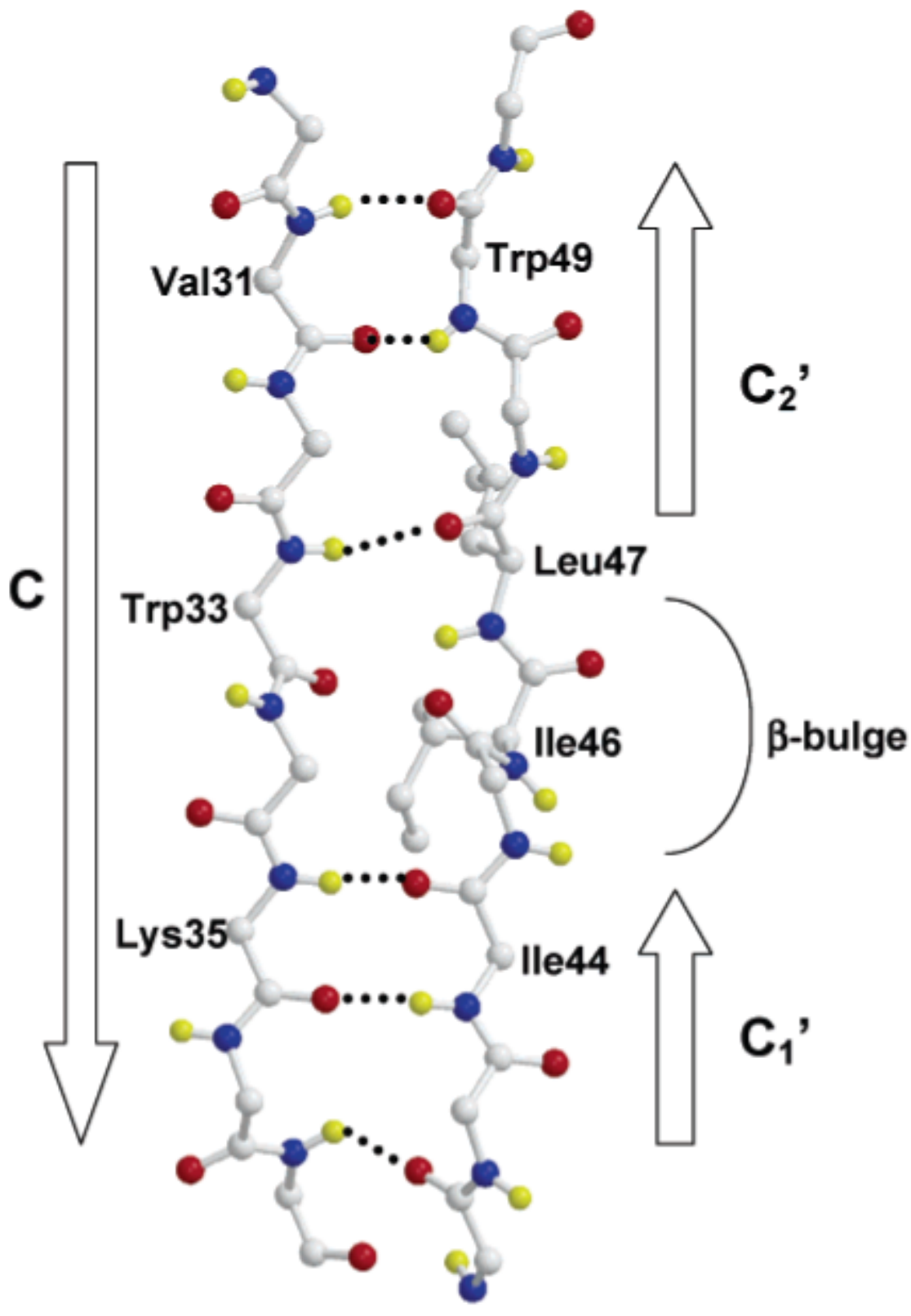

Figure 4.

Hydrogen bonds in the $\beta$-bulge region. The main-chain atoms of strands $\mathrm{C}$ and $\mathrm{C}^{\prime}$ are depicted by a ball-and-stick model. Carbon, hydrogen, nitrogen, and oxygen atoms are colored white, yellow, blue, and red, respectively. Main-chain hydrogen bonds between strands $\mathrm{C}$ and $\mathrm{C}$ ' are indicated by dotted lines. The $\beta$-bulge, formed by Glu 45 and Ile 46 , disrupts the hydrogen bonding pattern between strands $\mathrm{C}$ and $\mathrm{C}^{\prime}$. 
A

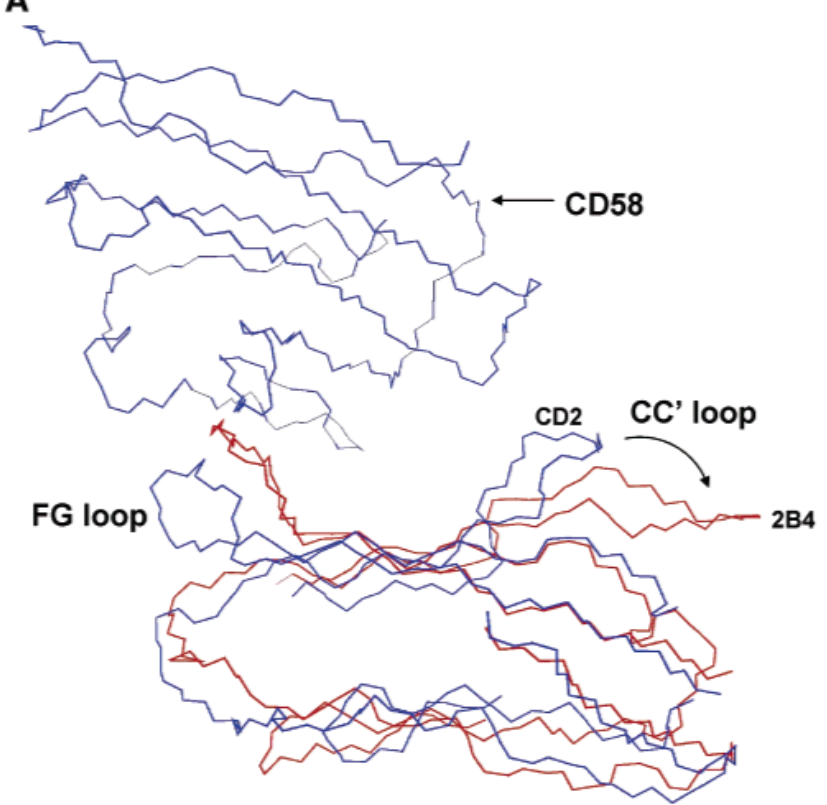

B
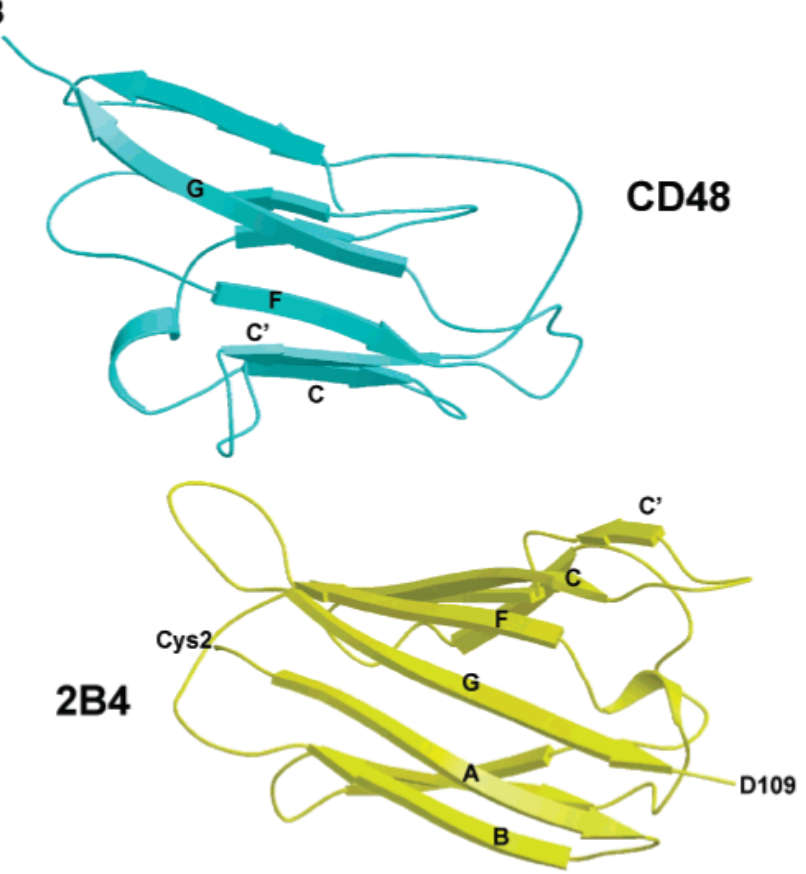

Figure 5.

(A) Overlay of main-chain structures of 2B4 (red) and CD2-CD58 complex (1qa9.pdb in blue). (B) Modeled three-dimensional structure of the 2B4-CD48 complex. The structure of CD48 was calculated on the basis of the known structure of CD58 (1qa9.pdb) using homology modeling. The modeled structure of CD48 was docked onto 2B4 by overlaying the CD48 and 2B4 structures on top of CD58 and CD2, respectively,in the complex. 


\section{Table 1}

Structural Statistics for the Ensemble of 15 Calculated Structures of 2B4

\begin{tabular}{|c|c|}
\hline NOE restraints (total) & 1891 \\
\hline intra $(|i-j|=0)$ & 722 \\
\hline medium $(1 \leq|i-j| \leq 4)$ & 506 \\
\hline long $(|i-j|>4)$ & 663 \\
\hline dihedral angle restraints $(\phi$ and $\psi)$ & 128 \\
\hline hydrogen bond restraints in $\beta$-sheet regions & 170 \\
\hline \multicolumn{2}{|l|}{ rmsd from ideal geometry } \\
\hline bond length $(\AA)$ & $0.0074 \pm 0.0004$ \\
\hline bond angles $\left({ }^{\circ}\right)$ & $2.25 \pm 0.02$ \\
\hline \multicolumn{2}{|l|}{ Ramachandran plot } \\
\hline most favored region $(\%)$ & 70 \\
\hline allowed regions $(\%)$ & 27 \\
\hline disallowed regions $(\%)$ & 3 \\
\hline \multicolumn{2}{|l|}{ rmsd of atom position from average structure } \\
\hline$\beta$-sheet regions (main chain atoms) $(\AA)$ & $0.4 \pm 0.05$ \\
\hline$\beta$-sheet regions (non-hydrogen atoms) $(\AA)$ & $1.1 \pm 0.08$ \\
\hline
\end{tabular}

